\title{
Accessing Chemo- and Regioselective Benzylic and Aromatic Oxidations by Protein Engineering of an Unspecific Peroxygenase
}

Anja Knorrscheidt, Jordi Soler, Nicole Hünecke, Pascal Püllmann, Marc Garcia-Borràs,* and Martin J. Weissenborn*

Cite This: ACS Catal. 2021, 11, 7327-7338

Read Online

ABSTRACT: Unspecific peroxygenases (UPOs) enable oxyfunctionalizations of a broad substrate range with unparalleled activities. Tailoring these enzymes for chemo- and regioselective transformations represents a grand challenge due to the difficulties in their heterologous productions. Herein, we performed protein engineering in Saccharomyces cerevisiae using the MthUPO from Myceliophthora thermophila. More than 5300 transformants were screened. This protein engineering led to a significant reshaping of the active site as elucidated by computational modelling. The reshaping was responsible for the increased oxyfunctionalization activity, with improved $k_{\text {cat }} / K_{\mathrm{m}}$ values of up to 16.5 -fold for the model substrate 5-nitro-1,3-benzodioxole. Moreover, variants were identified with high chemo- and regioselectivities in the oxyfunctionalization of aromatic and benzylic carbons, respectively. The benzylic hydroxylation was demonstrated to perform with enantioselectivities of up to $95 \% \mathrm{ee}$. The proposed evolutionary protocol and rationalization of the enhanced activities and selectivities acquired by MthUPO variants represent a step forward toward the use and implementation of UPOs in biocatalytic synthetic pathways of industrial interest.

KEYWORDS: chemoselectivity, unspecific peroxygenase, protein engineering, naphthoquinone, biocatalysis

\section{INTRODUCTION}

Fungal unspecific peroxygenases (UPOs) are heme-containing proteins that catalyze oxyfunctionalization reactions of a broad substrate scope via an oxyferryl active species known as compound I (Cpd I), analogous to hemeperoxidases and P450 monooxygenases (P450s). ${ }^{1-4}$ UPOs utilize hydrogen peroxide as a "prereduced" oxygen source and do not require additional reducing agents or reductase domains such as $\mathrm{P} 450$ s, which require $\mathrm{NAD}(\mathrm{P}) \mathrm{H}$ equivalents and electron transfer steps to activate molecular oxygen (Scheme 1$).^{5-7}$ This facile Cpd I generation and its high activities render UPOs as very promising biocatalysts. UPOs have demonstrated in the last two decades to be highly efficient biocatalysts for carbon, sulfur, and nitrogen oxyfunctionalizations. ${ }^{8-11}$ They can activate $\mathrm{C}-\mathrm{H}$ bonds of $\mathrm{sp}^{3}$-hybridized carbons enabling a homolytic cleavage.

The resulting carbon radical rapidly reacts with the ironbound $\mathrm{OH}$ group in a second step to form the hydroxylation product and recover the resting state $\mathrm{Fe}$ (III) center (Scheme 1). The functionalization of $\mathrm{C}-\mathrm{C}$ double bonds results in an epoxide formation, while for aromatic oxidations, the initial epoxidation follows a spontaneous rearomatization resulting in a formal hydroxylation product. Aromatic oxidations could also lead to the respective quinones, such as naphthoquinone from naphthalene, which is assumed to proceed via the 1-naphthol formation followed by a peroxidase-type single electron oxidation. $^{12,13}$

While the activity and stereoselectivity of UPO-catalyzed reactions are auspicious for future synthetic and industrial applications, low regio- and chemoselectivities mostly afford product mixtures hampering their direct utilization.

Examples for poor regioselectivities by most UPOs are the hydroxylations of saturated fatty acids, ${ }^{14}$ alkanes, ${ }^{15,16}$ steroids, ${ }^{17}$ and vitamin D3. ${ }^{18}$

Low chemoselectivities are observed for unsaturated fatty acids $^{14}$ and a range of linear and cyclic alkenes. ${ }^{19,20}$ Although advances have been made by engineering new P450 variants, ${ }^{21,22}$ there is a need to develop more selective UPOs to overcome these limitations.

The shortcomings of UPOs are mostly addressed by smart substrate selections. Although, for example, toluene leads to a mixture of ortho, para, and benzylic hydroxylations with AaeUPO from Agrocybe aegerita (syn. Cyclocybe aegerita), utilizing phenylethane resulted in the specific hydroxylation of

Received: February 22, 2021

Revised: $\quad$ May 21, 2021

Published: June 7, 2021 
Scheme 1. Formation of the Catalytically Active Oxyferryl Species (Cpd I) in P450s and UPOs and the Oxyfunctionalization of $\mathrm{sp}^{2}$ - and $\mathrm{sp}^{3}$-Hybridized Carbons

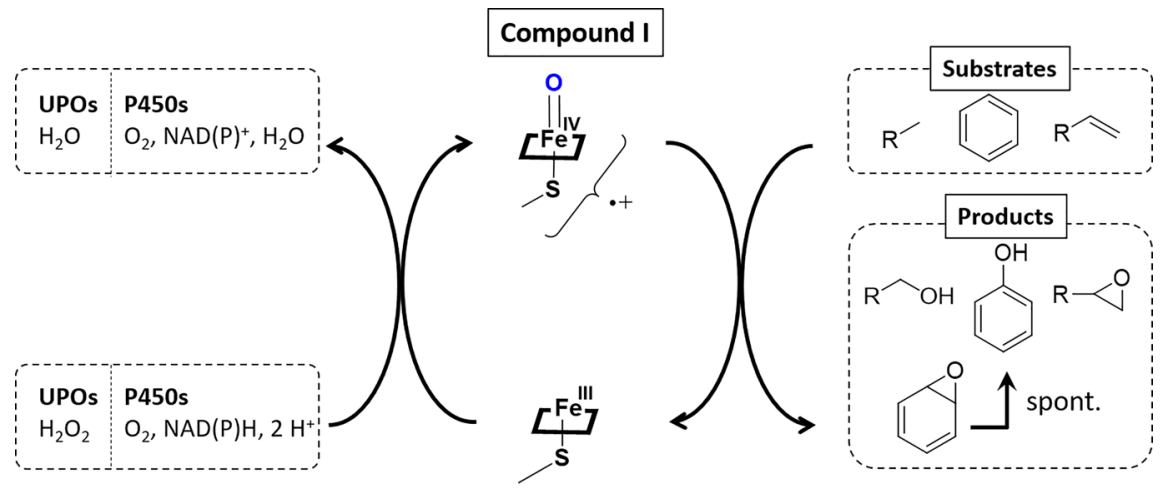

Scheme 2. Protein Engineering of UPOs for Chemoselective Oxyfunctionalizations
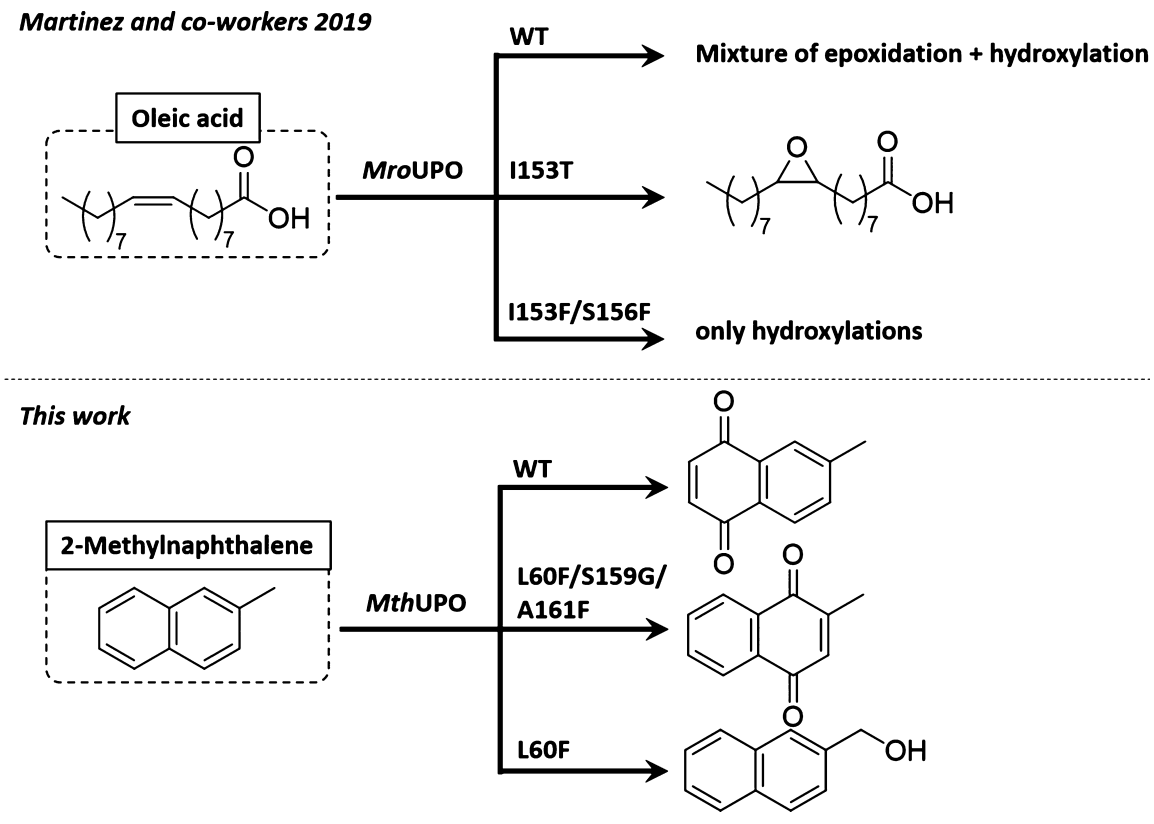

the benzylic carbon. ${ }^{19,23}$ This change in the selectivity trend was likely due to the higher reactivity of the secondary $\mathrm{C}\left(\mathrm{sp}^{3}\right)-\mathrm{H}$ of the benzylic phenylethane [estimated bond dissociation energy (BDE) $83.0 \mathrm{kcal} / \mathrm{mol}$ compared to the respective primary $\mathrm{C}-\mathrm{H}$ bond in toluene $(\mathrm{BDE} 86.7 \mathrm{kcal} / \mathrm{mol}$, Figure S17)].

To increase the applicability of UPOs as useful biocatalysts, accessing substrate-independent and selective hydroxylations is of utmost importance. This selectivity increase could be achieved by protein engineering. Protein engineering encompasses the random or rational variation of enzyme amino acid sequences to alter their properties such as activity, substrate scope, selectivity, stability and tolerance to different reaction conditions. In most cases, altering the protein for desired activities requires the assessment of large enzyme libraries. $^{2,22,24,25}$ The development of a high-throughput compatible, heterologous UPO expression system in Saccharomyces cerevisiae enabled protein engineering of UPOs. ${ }^{26,27}$ With this advancement, various impressive directed evolution endeavors were pursued aiming toward improved UPO expression, ${ }^{27}$ neutral drift, ${ }^{28}$ and efficient hydroxypropranolol formation. ${ }^{29,30}$

Recently, a first approach addressing the chemoselectivity issues of UPOs has been reported. ${ }^{31}$ An Escherichia coli expression system was developed, which, although thus far not high-throughput capable, allowed first studies on a few point mutations of MroUPO from Marasmius rotula. Using molecular dynamics (MD) simulations to explore substrate-binding pathways, heme channel modifications were predicted to influence the epoxidation and hydroxylation, respectively, on the unsaturated fatty acid oleic acid. While the wild type showed hydroxylated and epoxidized products, variant I153T had a strongly enriched epoxide formation. The double mutant $\mathrm{I} 153 \mathrm{~F} / \mathrm{S} 156 \mathrm{~F}$, on the other hand, completely abolished the epoxide formation and exclusively showed hydroxylation regioisomers (Scheme 2).

We have recently established the heterologous expression of a set of UPOs in S. cerevisiae and Pichia pastoris. ${ }^{32}$ The therein discovered MthUPO from the thermophilic fungus Myceliophthora thermophila demonstrated the thus far highest shake flask expression yields allowing a facile microtiter plate-based analysis. Contrary to the well-established AaeUPO, MthUPO showed an altered substrate specificity. AaeUPO exhibited mostly single hydroxylation of naphthalene to naphthol ${ }^{33}$ and the same applies for the secretion variant AaeUPO*. ${ }^{12,32}$ AaeUPO* also revealed the overoxidation to 1,4-naphthoquinone in small amounts caused by a sequential reaction after the 
1-naphthol formation. However, different product ratios are observed for MthUPO. This enzyme catalyzed the naphthalene oxyfunctionalization yielding 1-naphthol and 1,4-naphthoquinone almost in a $1: 1$ ratio. $^{32}$ For benzylic hydroxylations, AaeUPO demonstrated the highest product yields for phenylethane and -propane but strongly abolished and diminished benzylic product formations for phenylbutane and -pentane, respectively. MthUPO showed the opposite tendency: the highest activities were observed for phenylbutane and -pentane and the lowest for phenylethane. Due to the ability of the MthUPO to perform aromatic as well as benzylic hydroxylations efficiently, we hypothesized that by protein engineering, variants could be designed possessing distinct active site geometries enabling the control of the chemoselectivities toward either of the competing transformations. We were interested in 2-methylnaphthalene as a target structure as naphthalene is readily oxidized by MthUPO and therefore provides a good starting point and also has an additional methyl group that offers a position for benzylic hydroxylation. Moreover, the oxidation product 2-methyl-1,4-naphthoquinone is vitamin $\mathrm{K}_{3}$ and hence of industrial interest. ${ }^{34}$ To enable a colorimetric high-throughput screening, the 5-nitro-1,3benzodioxole (NBD) assay $^{35}$ was selected as it utilizes a substrate that bears an aromatic ring system, an $\mathrm{sp}^{3}$-carbon, and has a comparable size as naphthalene. A naphthalenebased colorimetric assay would have been based solely on the chemically more facile aromatic hydroxylation and is hence less suitable to identify variants for benzylic and aromatic hydroxylations.

In the present work, a prescreening of single and double saturation libraries was employed to identify relevant positions for activity and selectivity in the active site and the entrance channel of MthUPO. The best-performing variants were selected and combined in a large recombination library. In total, more than 5300 transformants were assessed, which led to the discovery of variants with improved activities. Computational modeling based on extensive MD simulations suggested essential changes in the active site due to mutations that directly impacted preferential substrate binding poses. When naphthalene and its derivatives were tested with the newly engineered variants, different chemoselective oxidation patterns at the benzylic and aromatic positions, respectively, were found. MD simulations described that different catalytically relevant binding poses are explored in each variant by 2 methylnaphthalene, indane, and related tested substrates, which are equivalent to those characterized for the NBD model substrate. The control achieved on the accessible binding poses for the substrates and their specific positioning toward the catalytic Cpd I active species is proposed to be responsible for controlling the chemo- and stereoselectivity observed in these aromatic and benzylic oxidations.

\section{RESULTS AND DISCUSSION}

Based on a homology model for MthUPO, a total of nine positions (L56, F59, L60, L86, F154, T155, S159, A161, and L206) were saturated (Figure 1) using the Golden Mutagenesis technique with the web tool for primer design. ${ }^{36}$ The mutant library was transformed in $S$. cerevisiae producing the corresponding variants. We screened the library using the colorimetric NBD assay ${ }^{27,35}$ in combination with the recently established split-GFP analysis in yeast. ${ }^{37,48}$ The split-GFP ${ }^{38,48}$ system allows the direct quantification of protein concentrations. It consists of a 16 amino acid split-GFP tag, which is

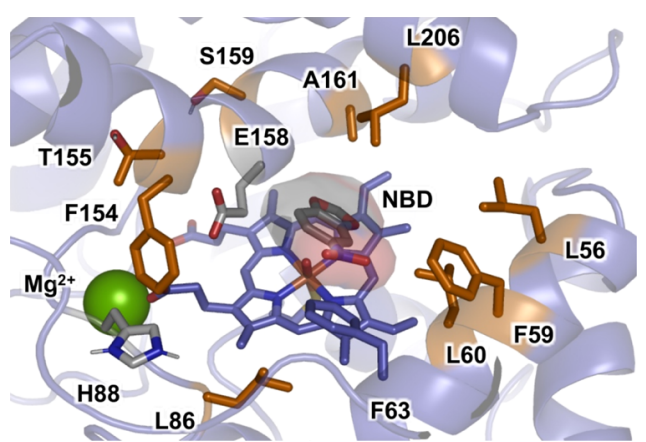

Figure 1. Active site arrangement of $M t h \mathrm{UPO}$ with the NBD substrate bound obtained from MD simulations based on the generated homology model. ${ }^{46}$ Important active site residues, catalytic residues, and NBD substrate are shown in sticks. The nine positions initially randomized are highlighted in orange, catalytic residues (H88 and E158) and NBD substrate are shown in gray, an important active site residue (F63) is shown in purple, and the structural $\mathrm{Mg}^{2+}$ ion is shown as a green sphere.

C-terminally attached to the protein of interest. By adding a truncated GFP, it recombines with the split-GFP tag and its resulting fluorescence restoration allows the quantification of the split-GFP-carrying protein.

The combination of the NBD and the split-GFP assay enabled the distinction between substrate conversion and protein secretion. Variations at the position L56 substantially influenced the expression of the enzyme. Only $52 \%$ of the analyzed transformants displayed a fluorescence response (Table S4). Site saturation at the position L60 yielded improved variants with superior TONs for the NBD conversion. The variants L60M (1.2-fold improvement relative to the wild type), L60Q (1.3-fold), and L60F (2.7-fold) showed the most noticeable improvements (Tables 1 and S5). The variant library of the position F154, which is located at the entrance channel, turned out to be a pivotal position for the NBD conversion.

Table 1. Catalytic Activity of MthUPO Variants for the Hydroxylation of $\mathrm{NBD}^{a}$

\begin{tabular}{lccr}
\multicolumn{1}{c}{ MthUPO variant } & conversion [\%] & TOF $\left[\mathrm{min}^{-1}\right]$ & TON \\
WT & 29 & 72 & 4340 \\
L60F & 77 & 194 & 11,610 \\
L60F/S159G/A161F & 84 & 210 & 12,590 \\
F59Q/L60M/S159G/F154A & 77 & 192 & 11,540 \\
F59Q/L60F/S159G ${ }^{b}$ & 76 & 379 & 22,760
\end{tabular}

$a_{\mathrm{TOF}}=$ turnover frequency, TON $=$ turnover number, standard deviation $<3.2 \%$, reaction conditions: $20 \mathrm{nM} \mathrm{MthUPO}$ variant, 300 $\mu \mathrm{M}$ NBD, $1 \mathrm{mM} \mathrm{H}_{2} \mathrm{O}_{2}, 100 \mathrm{mM} \mathrm{KPi}$ buffer ( $\mathrm{pH} 7$ ), 5\% acetone (v/ $\mathrm{v})$, measurement conditions: absorbance was measured at $425 \mathrm{~nm}$ for $1 \mathrm{~h}$ in triplicates, values were calculated with the corrected extinction coefficient of $10,870 \mathrm{M}^{-1} \mathrm{~cm}^{-1}$ (see Figure S2). ${ }^{b} 10 \mathrm{nM} \mathrm{MthUPO.}$

Even though $81 \%$ of the variants were secreted according to the split-GFP signal, only the rediscovered wild-type enzymes displayed activity (Figure S1, Table S4).

As the second step, we grouped two amino acid residues and saturated them simultaneously with a reduced codon degeneracy (NDT), thereby obtaining the double mutants L60F/F154I and L60F/F154V with a 1.2-fold improvement compared to the wild type (Table S5). 
The initial screening of the single and double saturation library provided us with the necessary insights for important residues for enzymatic catalysis. Residues, which had a positive or neutral influence on the NBD conversion, were selected for recombination. These positions and amino acids were F59Q, L60F/Q/M, A57I, F154I/V, S159N/G, and A161I/F. Inspired by Reetz' single-, double-, and triple-code saturation mutagenesis approaches, ${ }^{39,40}$ we chose to recombine all residues and variations in all combinatorial possibilities including the respective wild-type amino acid.

This combination led to 864 unique variants and required the screening of more than 2300 transformants.

The recombination library resulted in the discovery of triple and quadruple mutations with up to 16.5 -fold improved catalytic efficiencies $\left(k_{\text {cat }} / K_{\mathrm{m}}\right.$, Table 2$)$. All of the most active

Table 2. Biochemical Characterization of the MthUPO Wild Type and the Evolved Variants toward the Substrate NBD ${ }^{a}$

\begin{tabular}{lccc}
\multicolumn{1}{c}{ MthUPO variant } & $K_{\mathrm{m}}[\mu \mathrm{M}]$ & $k_{\text {cat }}\left[\mathrm{s}^{-1}\right]$ & $k_{\text {cat }} / K_{\mathrm{m}}\left[\mathrm{M}^{-1} \mathrm{~s}^{-1}\right]$ \\
WT & 386 & 7.1 & $1.9 \times 10^{4}$ \\
L60F & 110 & 2.9 & $2.7 \times 10^{4}$ \\
L60F/S159G/A161F & 422 & 132.2 & $3.1 \times 10^{5}$ \\
F59Q/L60M/S159G/F154A & 290 & 59.4 & $2.1 \times 10^{5}$ \\
F59Q/L60F/S159G & 303 & 47.0 & $1.6 \times 10^{5}$
\end{tabular}

${ }^{a}$ Standard deviation for the kinetics $<18 \%$, values were calculated with the corrected extinction coefficient of $10,870 \mathrm{M}^{-1} \mathrm{~cm}^{-1}$. For reaction conditions, see the Materials and Methods. For Michaelis-Menten plots, see the Supporting Information.

variants harbored amino acid exchanges at the L60 position (L60F/M) and the mutation S159G. The kinetic measurements revealed 8.2-fold (F59Q/L60F/S159G), 10.8-fold (F59Q/L60M/S159G/F154A), and 16.5-fold (L60F/S159G/ $\mathrm{A} 161 \mathrm{~F})$ increased $k_{\mathrm{cat}} / K_{\mathrm{m}}$ values relative to the wild type (Table 2). Although the $K_{\mathrm{m}}$ value of NBD was decreased or similar to the wild type, the values were significantly increased for $\mathrm{H}_{2} \mathrm{O}_{2}$ (Table S6). The $k_{\text {cat }}$ value for NBD, however, was substantially improved for the identified triple and quadruple mutants with an 18.6-fold increase for the variant L60F/ S159G/A161F relative to the wild type.

At this stage, we were interested in gaining some understanding of the changes induced by the mutations. Starting from the homology model for the MthUPO structure based on the solved crystal structure of the MroUPO (PDB: 5FUJ, $33.6 \%$ identity), we refined it by extensive $\mathrm{MD}$ simulations accumulating a total of $5 \mu \mathrm{s}(5000 \mathrm{~ns})$ of simulation time (see the Materials and Methods for details).
We then performed docking calculations that were used to obtain starting points for substrate-bound MD simulations in order to analyze the binding of NBD in the wild type and the selected variants L60F and L60F/S159G/A161F (Figures 2, S9 and S10). These simulations revealed a switch in the binding mode of NBD when moving from wild type to L60F and L60F/S159G/A161F. Due to the inclusion of bulkier, aromatic residues in the inner active site-first L60F and then A161Fthe NBD substrate was reoriented from its original more buried binding pose in the wild type to partially occupying the entrance channel in L60F/S159G/A161F. This new binding pose allows the NBD to better approach the oxyferryl Cpd I species in a near attack conformation for $\mathrm{C}-\mathrm{H}$ abstraction, thus facilitating the oxidation reaction.

With these new engineered variants possessing different active site cavities, we were intrigued to probe their influence on the regio- and chemoselectivity on naphthalene derivatives (Scheme 3). The most active variants characterized from the NBD colorimetric assay were selected, and an initial screening on a substrate panel based on naphthalene and its derivatives was performed by gas chromatography-mass spectrometry (GC-MS), resulting in significant changes in the oxidation patterns (Figures S4-S6).

Utilizing a syringe pump setup achieved more than 10,000 TONs with variant F59Q/L60F/S159G for the conversion of naphthalene to 1,4-naphthoquinone 1a (Scheme 3a). By increasing $\mathrm{H}_{2} \mathrm{O}_{2}$ equivalents, 2-hydroxy-1,4-naphthoquinone $\mathbf{1 b}$ was formed as a byproduct, which is a natural dye known as Lawsone. ${ }^{41}$ Naphthalene conversion by the yeast expression variant of AaeUPO was previously shown to result in the predominant formation of 1 - and 2-naphthol and 1,4naphthoquinone only as a minor byproduct. ${ }^{12}$

The biotransformation of 2-methylnaphthalene with the wild type led predominantly to 6-methyl-1,4-naphthoquinone (Figure S7). The variant L60F/S159G/A161F was able to shift the major product formation to 2-methyl-1,4-naphthoquinone (2a), also known as vitamin $\mathrm{K}_{3}$, demonstrating the regioselectivity of this variant (Scheme $3 \mathrm{~b}$ ). We were pleased that we also identify the L60F variant with the preference for the methyl hydroxylation of 2-methylnaphthalene. This variant showed altered chemoselectivity dramatically suppressing the aromatic hydroxylation of the naphthalene core while accessing the hydroxylation of the methyl group $(\mathbf{2 b})$ as the major product. Also, the overoxidation to the aldehyde was observed (2c, Scheme 3b).

To understand the switch in chemoselectivity when moving from $\mathrm{L} 60 \mathrm{~F}$ to $\mathrm{L} 60 \mathrm{~F} / \mathrm{S} 159 \mathrm{G} / \mathrm{A} 161 \mathrm{~F}$ variants, we performed

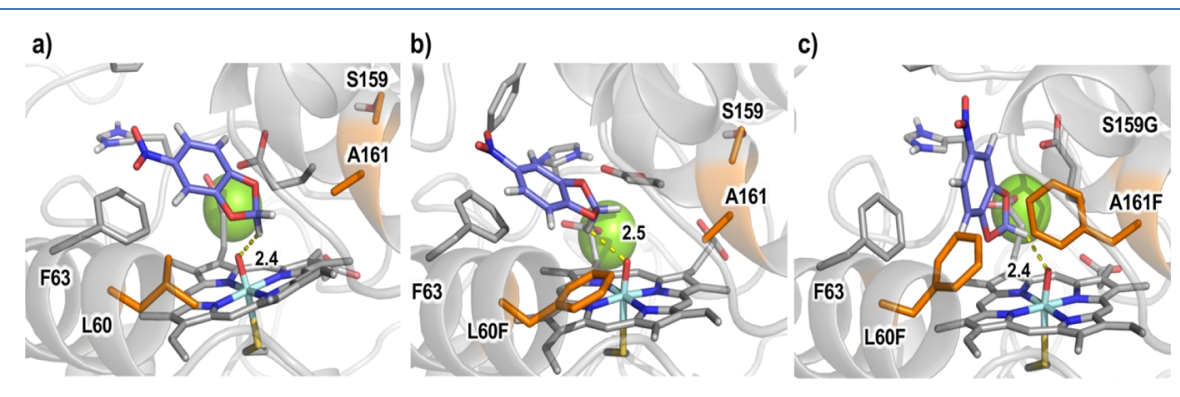

Figure 2. Active site arrangement of MthUPO and evolution of NBD's catalytically relevant binding modes in (a) wild type and the variants (b) L60F and (c) L60F/S159G/A161F as observed from MD simulations. Substrate, heme cofactor, and important active site and catalytic residues are shown in sticks. The three mutated positions are highlighted in orange, the NBD substrate is shown in purple, and the structural $\mathrm{Mg}^{2+}$ ion is shown as a green sphere. 
Scheme 3. Catalytic Activity of MthUPO Variants for the Hydroxylation of Naphthalene and Its Derivatives; ${ }^{a}$ (a) Transformation of Naphthalene with the Variant F59Q/L60F/S159G to 1,4-Naphthoquinone 1a and under Altered Conditions to Lawsone (1b), (b) 2-Methylnaphthalene Oxyfunctionalization with the Variant L60F/S159G/A161F Predominantly to 2-Methyl-1,4-naphthoquinone (2a, vitamin $\mathrm{K}_{3}$ ) and Using the Variant L60F towards the Benzylic Functionalization Leading to $2 b$ and 2c; $(c-e)$ Transformation with the Variant L60F/S159G/A161F of 1-Methyl-, 2Methoxy-, and 2-Bromonaphthalene, Respectively, Led to the Formation of the Naphthoquinone Derivatives 3a, 4a, and 5a; Only 2-Bromonaphthalene also Revealed Significant Oxyfunctionalizations of the Substituted Ring to Form 5b

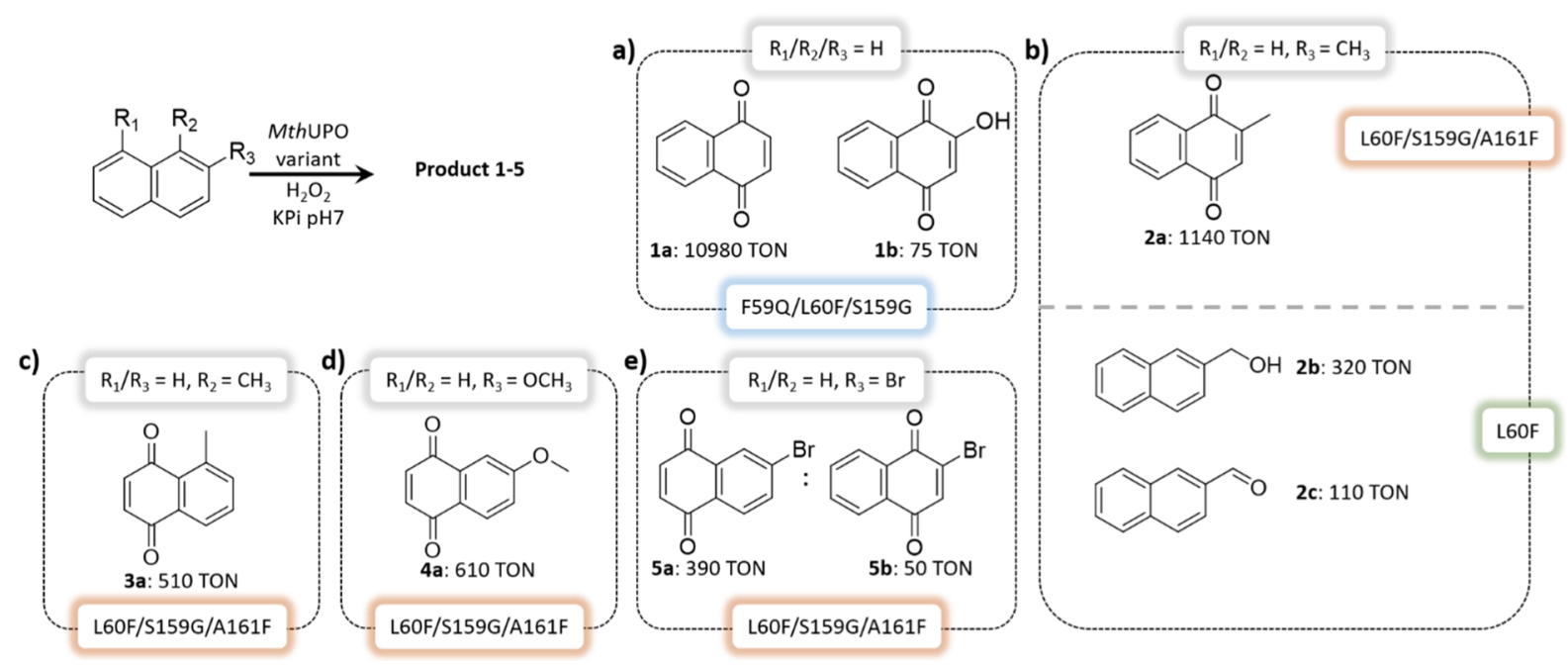

${ }^{a}$ Reaction conditions were $1 \mathrm{mM}$ substrate, $4 / 5 \mathrm{mM} \mathrm{H}_{2} \mathrm{O}_{2}$ (end concentration), 50-500 nM MthUPO variant, $100 \mathrm{mM} \mathrm{KPi} \mathrm{buffer} \mathrm{pH} \mathrm{7,} \mathrm{5 \%} \mathrm{(v/v)}$ acetone. Addition of $100-200 \mu \mathrm{L}$ of an $8-16 \mathrm{mM} \mathrm{H}_{2} \mathrm{O}_{2}$ stock solution via a syringe pump within $1-2 \mathrm{~h}$ and additional stirring for 30 min to overnight. Details are shown in Table S7. Standard deviation of triplicates $<5.2 \%$.

docking and MD simulations with 2-methylnaphthalene bound in both enzymes. MD simulations demonstrated that when 2methylnaphthalene is bound in the L60F variant, only the methyl group was able to approach the active $\mathrm{Fe}=\mathrm{O}$ species in a catalytically competent pose due to the presence of the bulky phenylalanine residue L60F (Figures 3 and S11). On the other hand, when 2-methylnaphthalene was bound into the variant L60F/S159G/A161F, a binding pose similar to the previously observed NBD positioning in this variant was observed (Figures 3 and S12). This change in substrate positioning is promoted by hydrophobic interactions occurring in the newly engineered active site, which is dominated by the presence of several aromatic residues (F59, F60, F63, and F161). Within this new binding pose, the substituted aromatic ring of 2methylnaphthalene is placed close enough to the oxyferryl (Cpd I) catalytic species to react while keeping the methyl group away from it. The different binding modes preferentially explored by 2-methylnaphthalene in these two variants are responsible for the observed switch in chemoselectivity (Figures S12 and S13).

When 1-methylnaphthalene was considered, a decrease in the TONs of $50 \%$ was observed, yielding the oxidation of the unsubstituted ring (Scheme 3c), as opposite to 2-methylnaphthalene. More surprisingly, also, substitutions at the 2 position of the naphthalene core led to the oxidation of the unsubstituted ring generating the 6-methoxy- (4a, Scheme 3d) and 6-bromo-1,4-naphthoquinone (5a, Scheme 3e) products with diminished TONs relative to 2-methylnaphthalene. For 2-bromo-naphthalene, 2-bromo-1,4-naphthoquinone $(\mathbf{5 b})$ was also detected as a byproduct.

To rationalize the different oxidation patterns observed for 1- and 2-substituted naphthalene derivatives, MD simulations were carried out. Simulations with the variant L60F/S159G/
A161F and 2-methoxy-naphthalene (Figures S13 and S14) revealed a preferential binding of the substrate in a region of the active site equivalent to the one observed for 2methylnaphthalene. However, due to the presence of the bulkier methoxy group at the 2 position and the presence of the $\mathrm{L} 60 \mathrm{~F}$ residue, the naphthalene core in 2-methoxynaphthalene needs to rotate slightly when approaching the $\mathrm{Fe}=\mathrm{O}$ active species in a catalytically competent pose. This rotation places the 2-methoxy group away from the L60F and the heme cofactor and brings the unsubstituted aromatic ring closer to the $\mathrm{Fe}=\mathrm{O}$ active species. Due to this proximity, a switch in the regioselectivity as compared to 2-methylnaphthalene occurred. A similar behavior was also observed for 1methylnaphthalene when bound in the variant L60F/S159G/ A161F in a catalytically competent pose (Figure S15).

Intrigued by the chemoselective benzylic hydroxylation catalyzed by $\mathrm{L} 60 \mathrm{~F}$, we tested this variant for the benzylic oxidation of indane and tetralin (1,2,3,4-tetrahydronaphthalene) investigating additional stereoselective control. L60F was able to convert indane with more than 8000 TONs and improved enantioselectivity for the (R)-1-indanol (5a) from $85 \%$ ee (wild type) to $95 \%$ ee (Tables 3 and S8). Interestingly, the examination of the variants L60F/S159G/A161F and F59Q/L60M/S159G/F154A revealed the loss of enantioselectivity and the excess in the formation of the $(S)$-enantiomer (Table S8). MD simulations with indane bound in the variant L60F characterized a preferential binding pose of indane that resembles the previously observed pose for 2-methylnaphthalene in L60F (Figures 3 and S16). Simulations showed that indane mainly interacts with the aromatic rings of F63 and L60F, establishing $\mathrm{C}-\mathrm{H} \cdots \pi$ interactions. These hydrophobic interactions keep the substrate in a preferred binding pose where only the pro- $R \mathrm{C}(1)-\mathrm{H}$ of the indane is close enough 
a)
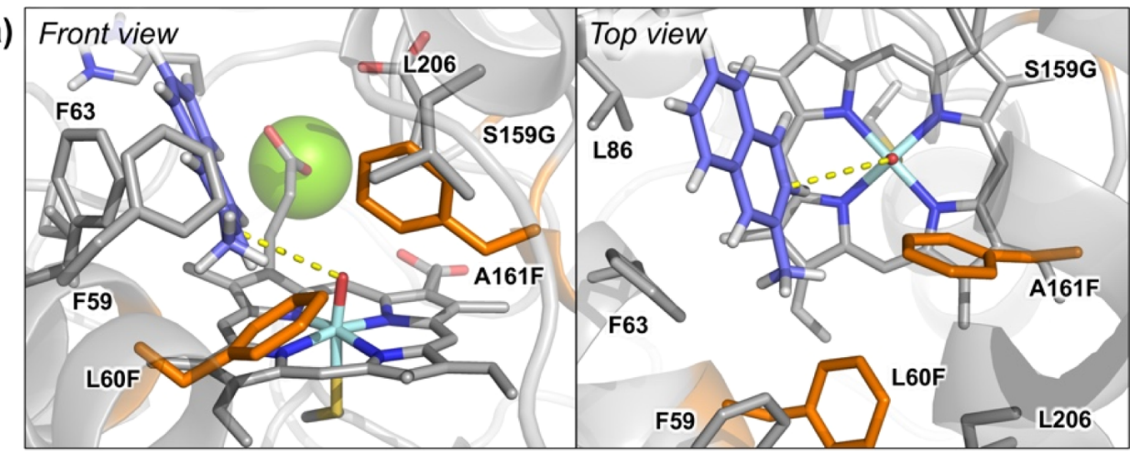

b)

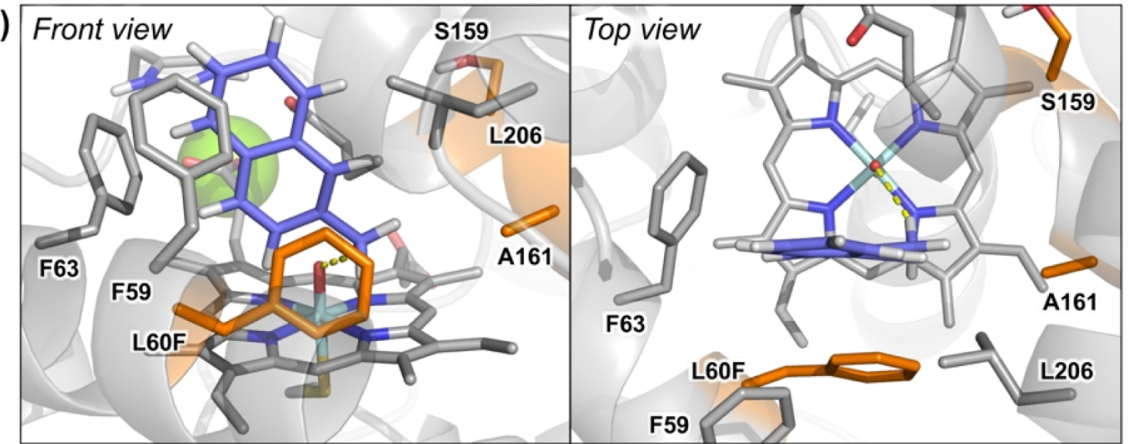

c) Front view
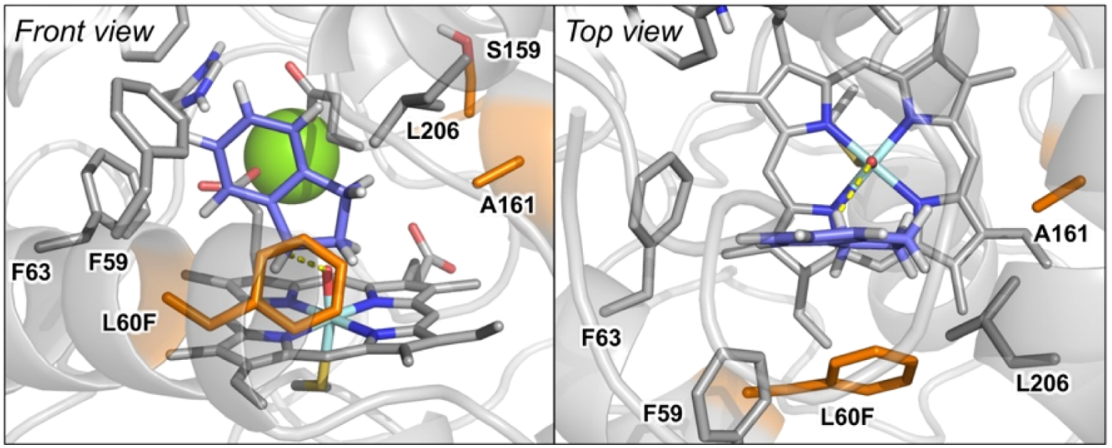

Figure 3. Catalytically relevant binding modes as characterized from MD simulations of (a) 2-methylnaphthalene in the L60F/S159G/A161F variant; (b) 2-methylnaphthalene in the L60F variant; and (c) indane in the L60F variant. Substrates, heme cofactor, and important active site and catalytic residues are shown in sticks. The three mutated positions are highlighted in orange, substrates are shown in purple, and the structural $\mathrm{Mg}^{2+}$ ion is shown in a green sphere.

and well-aligned to the oxyferryl species to be efficiently hydroxylated.

For the bioconversion of tetralin to the alcohol 6a, a substantially improved enantioselectivity for the $(R)$-enantiomer was detected for the variant L60F (74\% ee) relative to the wild type ( $45 \%$ ee, Figure S8). Similar to indane, a variant could be identified, which forms the $(S$ )-enantiomer (F59Q/ L60M/S159G/F154A) predominantly.

\section{CONCLUSIONS}

The most important landmarks of UPOs are their discovery, ${ }^{8}$ the development of smart hydrogen peroxide delivery systems ${ }^{2,19,42}$ that allow their implementation in biocatalytic processes using milder reaction conditions, and their heterologous expression making them easily accessible. $^{26,27,31,32}$ The next step toward the broader applicability of UPOs as useful biocatalysts is to access more chemo-, regio-, and stereoselective engineered UPO variants.

In this work, the recently characterized MthUPO was engineered using a protein evolution protocol that involves site saturation mutagenesis and an extensive recombination library, making use of a split-GFP and colorimetric assays and a highthroughput yeast expression system that allowed us to screen more than 5300 transformants. This led to MthUPO variants that achieve regioselective aromatic oxidations as well as chemoselective benzylic hydroxylations with 2-methylnaphthalene and other naphthalene derivatives.

Extensive $\mathrm{MD}$ simulations indicated that the origin of selectivity in these engineered MthUPO variants is a reshaping of the active site cavity that controls which specific binding modes are accessible for the tested aromatic substrates.

The newly engineered variant L60F/S159G/A161F binds 2methylnaphthalene in a catalytically relevant conformation that allows almost exclusively oxidation at the substituted ring. This binding mode yields the overoxidized 2-methyl-1,4-naphthoquinone (vitamin $\mathrm{K}_{3}$ ) product. Vitamin $\mathrm{K}_{3}$ (menadione) and the vitamin $\mathrm{K}$ family comprise 2-methyl-1,4-naphthoquinone derivatives, and the engineered selectivity provides a one-step direct route to access these molecules.

On the other hand, the variant L60F possesses an active site that does not allow the aromatic moiety of 2-methylnaphthalene to productively approach to the reactive oxyferryl 
Table 3. Catalytic Activity of MthUPO Variants toward Benzylic Hydroxylation Yielding Chiral Products ${ }^{a}$

${ }_{2}$

${ }^{a_{\mathrm{TON}}}=$ turnover number, standard deviation $<6.5 \%$, reaction conditions: $100 \mathrm{nM} \mathrm{MthUPO}$ variant, $1 \mathrm{mM}$ indane, $1 \mathrm{mM} \mathrm{H}_{2} \mathrm{O}_{2}, 100$ $\mathrm{mM} \mathrm{KPi} \mathrm{buffer} \mathrm{(} \mathrm{pH} 7), 5 \%$ acetone $(\mathrm{v} / \mathrm{v}), 1 \mathrm{~h}$ at $25^{\circ} \mathrm{C}$ in triplicates. ${ }^{b} 100 \mathrm{nM}$ MthUPO variant, $1 \mathrm{mM} \mathrm{1,2,3,4-tetrahydronaphthalene,} 1$ $\mathrm{mM} \mathrm{H}_{2} \mathrm{O}_{2}, 100 \mathrm{mM} \mathrm{KPi}$ buffer ( $\mathrm{pH} 7$ ), 5\% acetone (v/v), $1 \mathrm{~h}$ at 25 ${ }^{\circ} \mathrm{C}$ in triplicates. ${ }^{c} 100 \mathrm{nM}$ MthUPO variant, $1 \mathrm{mM} \mathrm{1,2,3,4-}$ tetrahydronaphthalene, $2 \mathrm{mM} \mathrm{H}_{2} \mathrm{O}_{2}, 100 \mathrm{mM} \mathrm{KPi}$ buffer ( $\mathrm{pH} 7$ ), $5 \%$ acetone $(\mathrm{v} / \mathrm{v}), 2 \mathrm{~h}$ at $25{ }^{\circ} \mathrm{C}$ in triplicates. ${ }^{d}$ Determined by chiral GC.

species, preferentially binding the substrate in a pose where only the benzylic position can react. This resulted in a highly chemoselective benzylic hydroxylation and partly overoxidation to the aldehyde. The variant L60F also exhibits improved enantioselective benzylic hydroxylation of indane, which is shown to preferentially bind in this variant in a catalytically competent pose similar to the one observed for 2methylnaphthalene.

The presented work demonstrates the protein engineering toward chemo-, regio-, and enantioselective oxyfunctionalizations catalyzed by fungal UPOs, paving the way toward the broader application of UPOs in enzyme cascades, organic chemistry, and industry.

\section{MATERIALS AND METHODS}

Chemicals. Solvents were used as provided without further purification from Carl Roth (Karlsruhe, DE) as GC ultragrade. The commercially available compounds were also used without further purification from the following suppliers: $\mathrm{N}, \mathrm{O}$-bis(trimethylsilyl)trifluoroacetamide (BSTFA, Macherey-Nagel, Düren, DE), hydrogen peroxide solution $[30 \%(\mathrm{w} / \mathrm{w})$ in $\mathrm{H}_{2} \mathrm{O}$, Sigma-Aldrich, St. Louis, US], cumene hydroperoxide (contains 20\% aromatic hydrocarbon, TCI, Tokyo, JP), tertbutyl hydroperoxide (70\% in water, TCI, Tokyo, JP), NBD (98\%, Sigma-Aldrich, St. Louis, US), naphthalene (99\%, Sigma-Aldrich, St. Louis, US), (R)-(-)-1-indanol (99\%, Sigma-Aldrich, St. Louis, US), (S)-(+)-1,2,3,4-tetrahydro-1naphthol (98\%, TCI, Tokyo, JP), 1,2,3,4-tetrahydronaphthalene (99\%, Fluka, Buchs, CH), 1-indanone (99\%, SigmaAldrich, St. Louis, US), indane (95\%, TCI, Tokyo, JP), 1- hydroxyindane (99\%, TCI, Tokyo, JP), $\alpha$-tetralone (96\%, Fluka, Buchs, CH), 2-methylnaphthalene (97\%, Sigma-Aldrich, St. Louis, US), 2-naphthaldehyde (98\%, TCI, Tokyo, JP), 2hydroxymethylnaphthalene (97\%, abcr, Karlsruhe, DE), 1methylnaphthalene (96\%, TCI, Tokyo, JP), 2-methyl-1,4naphthoquinone (98\%, Sigma-Aldrich, St. Louis, US), 1,4naphthoquinone (97\%, Sigma-Aldrich, St. Louis, US), 2methoxy-1,4-naphthoquinone (98\%, Sigma-Aldrich, St. Louis, US), 1,2,3,4-tetrahydro-1-naphthol (97\%, Sigma-Aldrich, St. Louis, US), 2-bromo-1,4-naphthoquinone (98\%, SigmaAldrich, St. Louis, US), 4-octanone (98\%, TCI, Tokyo, JP), 2-methoxynaphthalene (98\%, TCI, Tokyo, JP), and 2bromonaphthalene (97\%, Fluka, Buchs, $\mathrm{CH})$. As a buffer system, $50 \mathrm{mM}$ potassium phosphate $(\mathrm{KPi}) \mathrm{pH} 7$ was utilized as an aqueous phase for the bioconversions.

Gas Chromatography-Mass Spectrometry. Measurements were performed on a Shimadzu GCMS-QP2020 NX instrument (Shimadzu, Kyoto, JP) with a Lipodex E column $(25 \mathrm{~m} \times 0.25 \mathrm{~mm}$, Macherey-Nagel, Düren, DE) for the chiral and on an SH-Rxi-5Sil MS $(30 \mathrm{~m} \times 0.25 \mathrm{~mm}$, Shimadzu, Kyoto, JP) for the achiral measurements, whereas helium was utilized as the carrier gas. The samples were injected split-less $(1 \mu \mathrm{L})$ with a liner temperature of $280{ }^{\circ} \mathrm{C}$. The interface temperature was set to $290{ }^{\circ} \mathrm{C}$. Ionization was obtained by electron impact with a voltage of $70 \mathrm{~V}$, and the temperature of the ion source was $250{ }^{\circ} \mathrm{C}$. The oven temperature profile for each compound is shown in Table S2. The detector voltage of the secondary electron multiplier was adjusted in relation to the tuning results with perfluorotributylamine. The GC-MS parameters were controlled with GCMS Real Time Analysis, and for data evaluation, GCMS Postrun Analysis (GCMSsolution Version 4.45, Shimadzu, Kyoto, JP) was used. Calibration and quantification were implemented in the selected ion monitoring (SIM) mode with the corresponding $m / z$ traces, as shown in Table S2, in triplicates. As an internal standard, 4-octanone ( $1 \mathrm{mM}, \mathrm{m} / z$ 128) in EtOAc was utilized. The product formation of 5-methyl-1,4-naphthoquinone (3a) was confirmed by the consistent literature fragmentation pattern: ${ }^{43}$ MS (EI) $m / z 172,144,118,116,115$, 90. For product quantification of 5-methyl-1,4-naphthoquinone (3a), 6-methoxy-1,4-naphthoquinone (4a, MS (EI) $m / z: 188,160$, $134,106,63$ ), and 6-bromo-1,4-naphthoquinone (5a, MS (EI) $m / z: 384,382,296,294,266,264,73)$, the corresponding structural isomers menadione (2a), 2-methoxy-1,4-naphthoquinone (4b), and 2-bromo-1,4-naphthoquinone (5b) were utilized. Compound $\mathbf{1 b}$ was derivatized according to the standard procedure of Macherey-Nagel (Düren, DE) with BSTFA: therefore, the water was removed using an Eppendorf concentrator 5301 (Hamburg, DE) under vacuum at $60{ }^{\circ} \mathrm{C}$ for $1.5 \mathrm{~h}$. The resulting residue was dissolved in $100 \mu \mathrm{L}$ of pyridine with ultrasound for $5 \mathrm{~min}$, followed by the addition of $100 \mu \mathrm{L}$ of BSTFA. The derivatization reaction was accomplished at 80 ${ }^{\circ} \mathrm{C}$ for $20 \mathrm{~min}$ and the solution was directly utilized for GCMS analysis resulting in the literature known fragmentation pattern: ${ }^{44}$ MS (EI) $m / z 231,203$.

Single-Site Saturation Mutagenesis. Mutagenesis was performed using the Golden Mutagenesis technique ${ }^{36}$ combined with the "22c-trick" 45 for residue randomization. The transformations into $S$. cerevisiae were performed as described before. ${ }^{32}$

Double-Site Saturation Mutagenesis. The single-site saturation mutagenesis led to the identification of relevant amino acid residues, which were combined in a double-site 
saturation mutagenesis approach based on spatial proximity and their potential interactions. The positions L60/F154, I52/ A57, F59/L150, S159/A161, and F63/L86 were therefore simultaneously randomized using an NDT codon degeneracy utilizing the previously mentioned Golden Mutagenesis protocol.

Generation of a Recombination Library of the BestPerforming Variants. The best-performing variants from the single- and double-site saturation mutagenesis were chosen for recombination. For this approach, the best-performing amino acid residues were selected and randomized. The following positions were chosen: L60 (WT/F/Q/M), F59 (WT/Q), A57 (WT/I), F154 (WT/V/I), S159 (WT/G/N), and A161 (WT/I/F). The library was generated based on the previously mentioned Golden Mutagenesis protocol yielding 864 possible combinations.

Microtiter Plate Cultivation of $S$. cerevisiae. The MthUPO production was performed as described previously. ${ }^{32}$ The cell pellet was resuspended in the remaining supernatant, and glycerol was added to achieve a final concentration of $25 \%$ $(\mathrm{v} / \mathrm{v})$. The sealed microtiter plates were frozen by liquid nitrogen and stored at $-80{ }^{\circ} \mathrm{C}$ as a mother plate for subsequent hit verification.

Activity Screening via NBD Assay in the Microtiter Plate Format. The utilization of 5-nitro-1,3-benzodioxole for a colorimetric screening approach has been described before yielding the chromophore 4-nitrocatechol. ${ }^{27,35}$ The conditions were slightly modified: after centrifugation, $20 \mu \mathrm{L}$ of the supernatant from the microtiter plate cultivation was transferred to a polypropylene 96-well screening plate (Greiner BioOne, Kremsmünster, AT) and $180 \mu \mathrm{L}$ of the master mix was added [end concentrations: $100 \mathrm{mM} \mathrm{KPi}$ buffer $\mathrm{pH}$ 7, $300 \mu \mathrm{M}$ NBD, $1 \mathrm{mM} \mathrm{H}_{2} \mathrm{O}_{2}, 5 \%$ (v/v) acetone]. The absorption was detected for $1 \mathrm{~h}$ at $425 \mathrm{~nm}$ (interval: $30 \mathrm{~s}$ ) starting directly after the addition of the master mix using an absorbance reader (TECAN, Grödig, AT). The reaction endpoint was determined overnight. Improved MthUPO variants were identified by comparing the absorption values of the NBD assay and the fluorescence values of the split-GFP assay with the parental variant.

Split-GFP Assay. Protein normalization was performed employing the principle of a split-GFP normalization assay as described by Santos-Aberturas et al. ${ }^{47}$ with slight modifications as reported previously. ${ }^{32}$ Based on the split-GFP assay, the percentage of secreted variants could be calculated (Table S4).

Automated Data Evaluation and Verification. For the microtiter plate screening, including the NBD and split-GFP assay, an automated data evaluation by $\mathrm{R}$ Studio was utilized. Thereby, the best-performing variants were identified based on their respective endpoint after $1 \mathrm{~h}$ and overnight, their NBD slope, and their NBD/GFP correlation when compared to the parental variant. For the data verification, the best-performing variants were reproduced in a microtiter plate setup in triplicates. If the improved activity was confirmed, the protein was cultivated in the shake flask scale and purified for further characterization.

Shake Flask Cultivation and Protein Purification. The cultivation was performed as previously described. ${ }^{32}$ The samples were stored at $-20{ }^{\circ} \mathrm{C}$ until further utilization.

NBD Assay with a Purified Enzyme for TOF/TON Determination. The purified MthUPO variants were measured via the NBD assay under the following conditions: $20 \mathrm{nM}$ MthUPO variant (exception: F59Q/L60F/S159G with
$10 \mathrm{nM}), 300 \mu \mathrm{M} \mathrm{NBD}, 1 \mathrm{mM} \mathrm{H}_{2} \mathrm{O}_{2}, 100 \mathrm{mM} \mathrm{KPi}$ buffer $(\mathrm{pH}$ $7), 5 \%$ acetone $(\mathrm{v} / \mathrm{v})$. The turnover numbers (TONs), turnover frequency values, and conversions were determined after $1 \mathrm{~h}$. For determination of the catalytic performance, the TON, TOF, and conversion were calculated based on the corrected extinction coefficient of 4-nitrocatechol. The actual extinction coefficient was calculated by a calibration curve of 4nitrocatechol in $100 \mathrm{mM} \mathrm{KPi}$ buffer $(\mathrm{pH} 7)$ with $5 \%$ acetone $(\mathrm{v} / \mathrm{v})$ (Figure S2a) leading to $\varepsilon_{425 \mathrm{~nm} \text {, 4-nitrocatechol }}=11,289 \mathrm{M}^{-1}$ $\mathrm{cm}^{-1}$. This coefficient was corrected by the extinction coefficient of NBD $\varepsilon_{425 \mathrm{~nm}, \mathrm{NBD}}=419 \mathrm{M}^{-1} \mathrm{~cm}^{-1}$ (Figure S2b) yielding to the corrected coefficient of $\varepsilon_{425 \mathrm{~nm} \text {, corr }}=10,870 \mathrm{M}^{-1}$ $\mathrm{cm}^{-1}$, which can be utilized for the catalytic performance calculations

$$
\begin{aligned}
& \mathrm{TON}=\frac{[\text { product }]}{[\text { catalyst }]}\left[\frac{\mathrm{mol}}{\mathrm{mol}}\right] \\
& \mathrm{TOF}=\frac{\mathrm{TON}}{\text { time }}\left[\mathrm{min}^{-1}\right]
\end{aligned}
$$

Determination of Kinetic Parameters. To determine the kinetic parameters $K_{\mathrm{m}}$ and $k_{\text {cat }}$ the purified protein samples were utilized. The best-performing variants from the NBD screening were compared to each other: the enzyme concentration was set to $20 \mathrm{nM}$ for each variant for the $K_{\mathrm{m}}$ (NBD) determination. The only exception was the variant L60F where an enzyme concentration of $5 \mathrm{nM}$ was used. For the determination of the $K_{\mathrm{m}}$ for $\mathrm{H}_{2} \mathrm{O}_{2}, 20 \mathrm{nM}$ enzyme concentration was employed for all protein variants. For the $K_{\mathrm{m}}$ determination of the corresponding substrate, the second substrate was utilized in its saturation concentration. The velocity quantification was achieved in the linear range of the 4-nitrocatechol using the corrected $\varepsilon_{425 \mathrm{~nm} \text {, corr }}=10,870 \mathrm{M}^{-1}$ $\mathrm{cm}^{-1}$ by applying automated path length correction in the microtiter plate. The nonlinear regression using the Michaelis-Menten model was performed with the aid of SigmaPlot (Version 14.0, Germany) yielding kinetic parameters $v_{\max }, K_{\mathrm{m}}$, and $R^{2}$.

Thermostability Measurements. Thermostability measurements were performed as described before. ${ }^{32}$

Initial Oxyfunctionalization Comparison between MthUPO and the Best-Performing Variants from the NBD Assay. For the identification of the best-performing variant toward the hydroxylation of naphthalene and its derivatives, an initial approach with the direct addition of $\mathrm{H}_{2} \mathrm{O}_{2}$ (without a syringe pump setup) was chosen. The following conditions were adjusted: $500 \mathrm{nM}$ MthUPO variant, $1 \mathrm{mM}$ $\mathrm{H}_{2} \mathrm{O}_{2}, 1 \mathrm{mM}$ of the corresponding substrate (see Figures S6$\mathrm{S} 8$ ), $100 \mathrm{mM} \mathrm{KPi} \mathrm{pH} \mathrm{7,} 1 \mathrm{~h}$ at $25{ }^{\circ} \mathrm{C}$. The reaction was quenched by the addition of $400 \mu \mathrm{L}$ of $n$-hexane with benzyl alcohol as the internal standard. The corresponding samples were analyzed in the GC-MS scan mode, and the products were identified by library comparison. For quantification and product confirmation, the syringe pump setup was utilized.

Bioconversion of Naphthalene and Naphthalene Derivatives Using a Syringe Pump System. With a syringe pump system, the product formation could be increased compared to the direct addition of $\mathrm{H}_{2} \mathrm{O}_{2}$ (initial approach). The conditions were adjusted for each reaction setup and are shown in Table S7. For the $\mathrm{H}_{2} \mathrm{O}_{2}$ addition, a programmable syringe pump from Chemyx Inc. (Model: Fusion 101R, Stafford, US) was utilized. The reaction and addition were performed under continuous stirring at room 
temperature. The extraction was accomplished by the addition of $400 \mu \mathrm{L}$ of EtOAc (containing $1 \mathrm{mM}$ 4-octanone as an internal standard) at the end of the reaction. After $30 \mathrm{~s}$ of vortexing, the organic layer was transferred for GC-MS analysis.

Bioconversion of Indane and 1,2,3,4-Tetrahydronaphthalene. For the bioconversion of these substrates, no syringe pump system was needed. The reaction was started by the addition of $\mathrm{H}_{2} \mathrm{O}_{2}$. The hydroxylation and overoxidation to the ketone were performed under the following conditions: $100 \mathrm{nM}$ L60F, $1 \mathrm{mM}$ indane, $1 \mathrm{mM} \mathrm{H}_{2} \mathrm{O}_{2}, 100 \mathrm{mM} \mathrm{KPi} \mathrm{pH} \mathrm{7,}$ $5 \%$ acetone $(v / v), 1 \mathrm{~h}$ at $25{ }^{\circ} \mathrm{C}$ in triplicates. For the hydroxylation of 1,2,3,4-tetrahydronaphthalene, the conditions were adapted from the indane bioconversion. The bestperforming overoxidation of 1,2,3,4-tetrahydronaphthalene to the $\alpha$-tetralone was accomplished by MthUPO F59Q/L60M/ S159G/F154A with a final concentration of $2 \mathrm{mM} \mathrm{H}_{2} \mathrm{O}_{2}$. The extraction was achieved by the addition of $400 \mu \mathrm{L}$ of EtOAc (containing $1 \mathrm{mM}$ 4-octanone as an internal standard) at the end of the reaction. After $30 \mathrm{~s}$ of vortexing, the organic layer was transferred for GC-MS analysis. Quantification of the products was carried out on an SH-Rxi-5Sil MS column under the previously mentioned GC-MS conditions. The ee determination was carried out on a Lipodex E column.

Homology Model and MD Simulations. The homology model for the MthUPO structure (245 AA, + TwinStrepGFP11 tag) has been constructed based on the solved crystal structure of the UPO from $M$. rotula (MroUPO, PDB: 5FUJ, $34 \%$ identityand $46 \%$ similarity) using the homology server SWISS-MODEL. ${ }^{48}$ The resulting homology model has been further refined with extensive MD simulations based on five independent replicas of $1,000 \mathrm{~ns}$ each, accumulating a total of $5 \mu$ s of simulation time. MD simulations in explicit water were performed using the AMBER18 package. ${ }^{49}$ Parameters for the different substrates (NBD, 2-methylnaphthalene, 1-methylnaphthalene, 2-methoxynaphthalene, and indane) were generated within the antechamber ${ }^{50}$ module in AMBER18 package using the general AMBER force field (gaff), ${ }^{51}$ with partial charges set to fit the electrostatic potential generated at the B3LYP/6-31G(d) level using the RESP model. ${ }^{52}$ The charges were calculated according to the Merz-SinghKollman scheme $\mathrm{s}^{53,54}$ using the Gaussian 09 package. Parameters for the heme Cpd I and the axial Cys were taken from reference. ${ }^{55}$ The protein was solvated in a preequilibrated cubic box with a $12 \AA$ buffer of TIP3P ${ }^{56}$ water molecules using the AMBER18 leap module, resulting in the addition of $\sim 17,500$ solvent molecules. The systems were neutralized by the addition of explicit counterions $\left(\mathrm{Na}^{+}\right.$and $\mathrm{Cl}^{-}$). All subsequent calculations were carried out using the AMBER force field 14 Stony Brook (ff14SB). ${ }^{57}$ A two-stage geometry optimization approach was performed. The first stage minimizes the positions of solvent molecules and ions imposing positional restraints on the solute by a harmonic potential with a force constant of $500 \mathrm{kcal} \mathrm{mol}^{-1} \AA^{-2}$, and the second stage is an unrestrained minimization of all the atoms in the simulation cell. The systems were gently heated using six $50 \mathrm{ps}$ steps, incrementing the temperature by $50 \mathrm{~K}$ for each step $(0-300 \mathrm{~K})$ under constant-volume and periodic-boundary conditions. Water molecules were treated with the SHAKE algorithm such that the angle between the hydrogen atoms was kept fixed. Long-range electrostatic effects were modeled using the particle-mesh-Ewald method. ${ }^{58}$ An 8 A cutoff was applied to Lennard-Jones and electrostatic interactions. Harmonic restraints of $10 \mathrm{kcal} \cdot \mathrm{mol}^{-1}$ were applied to the solute, and the Langevin equilibration scheme was used to control and equalize the temperature. The time step was kept at $1 \mathrm{fs}$ during the heating stages, allowing potential inhomogeneities to self-adjust. Each system was then equilibrated for $2 \mathrm{~ns}$ with a 2 fs time step at a constant pressure of $1 \mathrm{~atm}$ and a temperature of $300 \mathrm{~K}$ without restraints. Once the systems were equilibrated in the NPT ensemble, production trajectories were then run under the NVT ensemble and periodicboundary conditions. In particular, a total of $5000 \mathrm{~ns}$ for wild-type MthUPO were accumulated from five independent replicas (1000 ns each); finally, a total of $750 \mathrm{~ns}$ from three independent replicas were accumulated for L60F and L60F/ S159G/A161F variants (250 each). Consequently, an extensive conformational sampling based on long timescale MD trajectories (1000 ns) and five different $\mathrm{MD}$ replicas for wild-type MthUPO has been carried out to refine the initial homology model. From this accumulated simulation time, the most representative structure of MthUPO was obtained by clustering analysis based on the protein backbone RMSD. This representative structure was used for further MD simulations, analyses, and preparation of the other studied variants. Trajectories were processed and analyzed using the cpptraj ${ }^{59}$ module from Ambertools utilities.

Docking and Protocol Used for Substrate-Bound MD Simulations. Docking calculations were performed using AutoDock Vina. ${ }^{60}$ Representative structures for the most populated clusters (based on backbone RMSD clustering analysis) obtained from $\mathrm{MD}$ simulations carried out in the apo state were used, and docking predictions were then utilized as starting points for substrate-bound MD simulations. To avoid substrate diffusion outside the enzyme active site and to sample catalytically competent binding poses, a $100 \mathrm{kcal}$. $\mathrm{mol}^{-1} \cdot \AA^{-2}$ restraint is applied when the distances between the center of mass of the substrate and the $\mathrm{O}$ atom of the $\mathrm{Fe}=\mathrm{O}$ in Cpd I are greater than $6 \AA$ (for indane) or $6.7 \AA$ (for naphthalene derivatives). No restraints were used in NBD substrate-bound simulations. The same protocol for MD simulations described above has been employed, accumulating a total of $300 \mathrm{~ns}$ of production trajectories from three independent replicas for all substrate-bound studies.

Quantum Mechanics Calculations. Density functional theory calculations were carried out using Gaussian 09. ${ }^{61}$ Geometry optimizations and frequency calculations were performed using the (U)B3LYP ${ }^{62-64}$ functional with the 6$31 \mathrm{G}(\mathrm{d})$ basis set on all atoms. The stationary points were verified as minima by a vibrational frequency analysis. Enthalpies and entropies were calculated for 1 atm and 298.15 K. Single-point energy calculations were performed using the functional (U)B3LYP with the Def2TZVP basis set on all atoms and within the CPCM polarisable conductor model (dichloromethane, $\varepsilon=8.9)^{65,66}$ to have an estimation of the dielectric permittivity in the enzyme active site. ${ }^{67}$ BDEs were calculated as the standard enthalpic change in the following process at $298 \mathrm{~K}$ (indane $\rightarrow$ indane $e^{\bullet}+\mathrm{H}^{\bullet}$ ), which provides an estimation of the strength of the $\mathrm{C}-\mathrm{H}$ bond under study. Different electronic states (singlet close-shell for indane and doublet for both radical species) have been considered.

\section{ASSOCIATED CONTENT}

\section{SI Supporting Information}

The Supporting Information is available free of charge at https://pubs.acs.org/doi/10.1021/acscatal.1c00847. 
Strategies for primer design, sequences of the utilized UPOs, kinetic plots, GC parameters and original GC chromatograms, activities and selectivities of all tested variants, reaction conditions, calibration curves, and figures of docking studies and $\mathrm{MD}$ simulations (PDF)

\section{AUTHOR INFORMATION}

\section{Corresponding Authors}

Marc Garcia-Borràs - Institut de Química Computacional $i$ Catàlisi and Departament de Química, Universitat de Girona, 17003 Girona, Catalonia, Spain; ○ orcid.org/ 0000-0001-9458-1114; Email: marc.garcia@udg.edu

Martin J. Weissenborn - Bioorganic Chemistry, Leibniz Institute of Plant Biochemistry, 06120 Halle, Germany; Institute of Chemistry, Martin Luther University HalleWittenberg, 06120 Halle, Germany; 이이.org/00000002-1200-4485; Email: martin.weissenborn@ipb-halle.de

\section{Authors}

Anja Knorrscheidt - Bioorganic Chemistry, Leibniz Institute of Plant Biochemistry, 06120 Halle, Germany

Jordi Soler - Institut de Química Computacional i Catàlisi and Departament de Química, Universitat de Girona, 17003 Girona, Catalonia, Spain

Nicole Hünecke - Bioorganic Chemistry, Leibniz Institute of Plant Biochemistry, 06120 Halle, Germany

Pascal Püllmann - Bioorganic Chemistry, Leibniz Institute of Plant Biochemistry, 06120 Halle, Germany

Complete contact information is available at:

https://pubs.acs.org/10.1021/acscatal.1c00847

\section{Notes}

The authors declare no competing financial interest.

\section{ACKNOWLEDGMENTS}

M.J.W., A.K., and N.H. thank the Bundesministerium für Bildung und Forschung ("Biotechnologie 2020+ Strukturvorhaben: Leibniz Research Cluster”, 031A360B) for generous funding. P.P. thanks the Landesgraduiertenförderung SachsenAnhalt for a Ph.D. scholarship. M.G.-B. thanks the Generalitat de Catalunya AGAUR for a Beatriu de Pinós H2020 MSCACofund 2018-BP-00204 project and the Spanish MICINN (Ministerio de Ciencia e Innovación) for PID2019-111300GAI00 project, and J.S. thanks the Spanish MIU (Ministerio de Universidades) for a predoctoral FPU fellowship FPU18/ 02380. The computer resources at MinoTauro and the Barcelona Supercomputing Center BSC-RES are acknowledged (RES-QSB-2019-3-0009 and RES-QSB-2020-2-0016).

\section{REFERENCES}

(1) Hobisch, M.; Holtmann, D.; Gomez de Santos, P.; Alcalde, M.; Hollmann, F.; Kara, S. Recent developments in the use of peroxygenases - Exploring their high potential in selective oxyfunctionalisations. Biotechnol. Adv. 2020, 107615.

(2) Ni, Y.; Fernández-Fueyo, E.; Baraibar, A. G.; Ullrich, R.; Hofrichter, M.; Yanase, H.; Alcalde, M.; van Berkel, W. J. H.; Hollmann, F. Peroxygenase-Catalyzed Oxyfunctionalization Reactions Promoted by the Complete Oxidation of Methanol. Angew. Chem., Int. Ed. 2016, 55, 798-801.

(3) Hofrichter, M.; Kellner, H.; Herzog, R.; Karich, A.; Liers, C.; Scheibner, K.; Kimani, V. W.; Ullrich, R. Fungal Peroxygenases: A Phylogenetically Old Superfamily of Heme Enzymes with Promiscuity for Oxygen Transfer Reactions. In Grand Challenges in Fungal
Biotechnology; Nevalainen, H., Ed.; Springer International Publishing: Cham, 2020; pp 369-403.

(4) Hofrichter, M.; Kellner, H.; Pecyna, M. J.; Ullrich, R. Fungal unspecific peroxygenases: heme-thiolate proteins that combine peroxidase and cytochrome p450 properties. Adv. Exp. Med. Biol. 2015, 851, 341-368.

(5) Hannemann, F.; Bichet, A.; Ewen, K. M.; Bernhardt, R. Cytochrome P450 systems-biological variations of electron transport chains. Biochim. Biophys. Acta, Gen. Subj. 2007, 1770, 330-344.

(6) Hoffmann, S. M.; Weissenborn, M. J.; Gricman, Ł.; Notonier, S.; Pleiss, J.; Hauer, B. The Impact of Linker Length on P450 Fusion Constructs: Activity, Stability and Coupling. ChemCatChem 2016, 8, 1591-1597.

(7) Belsare, K. D.; Horn, T.; Ruff, A. J.; Martinez, R.; Magnusson, A.; Holtmann, D.; Schrader, J.; Schwaneberg, U. Directed evolution of P450cin for mediated electron transfer. Protein Eng., Des. Sel. 2017, 30, 119-127.

(8) Ullrich, R.; Nüske, J.; Scheibner, K.; Spantzel, J.; Hofrichter, M. Novel haloperoxidase from the agaric basidiomycete Agrocybe aegerita oxidizes aryl alcohols and aldehydes. Appl. Environ. Microbiol. 2004, 70, 4575-4581.

(9) Wang, Y.; Lan, D.; Durrani, R.; Hollmann, F. Peroxygenases en route to becoming dream catalysts. What are the opportunities and challenges? Curr. Opin. Chem. Biol. 2017, 37, 1-9.

(10) Hofrichter, M.; Ullrich, R. Oxidations catalyzed by fungal peroxygenases. Curr. Opin. Chem. Biol. 2014, 19, 116-125.

(11) Bormann, S.; Gomez Baraibar, A.; Ni, Y.; Holtmann, D.; Hollmann, F. Specific oxyfunctionalisations catalysed by peroxygenases: opportunities, challenges and solutions. Catal. Sci. Technol. 2015, 5, 2038-2052.

(12) Molina-Espeja, P.; Cañellas, M.; Plou, F. J.; Hofrichter, M.; Lucas, F.; Guallar, V.; Alcalde, M. Synthesis of 1-Naphthol by a Natural Peroxygenase Engineered by Directed Evolution. ChemBioChem 2016, 17, 341-349.

(13) Ullrich, R.; Hofrichter, M. Enzymatic hydroxylation of aromatic compounds. Cell. Mol. Life Sci. 2007, 64, 271-293.

(14) Babot, E. D.; del Río, J. C.; Kalum, L.; Martínez, A. T.; Gutiérrez, A. Oxyfunctionalization of aliphatic compounds by a recombinant peroxygenase from Coprinopsis cinerea. Biotechnol. Bioeng. 2013, 110, 2323-2332.

(15) Peter, S.; Kinne, M.; Wang, X.; Ullrich, R.; Kayser, G.; Groves, J. T.; Hofrichter, M. Selective hydroxylation of alkanes by an extracellular fungal peroxygenase. FEBS J. 2011, 278, 3667-3675.

(16) Olmedo, A.; Aranda, C.; del Río, J. C.; Kiebist, J.; Scheibner, K.; Martínez, A. T.; Gutiérrez, A. From Alkanes to Carboxylic Acids: Terminal Oxygenation by a Fungal Peroxygenase. Angew. Chem., Int. Ed. 2016, 55, 12248-12251.

(17) Babot, E. D.; del Río, J. C.; Cañellas, M.; Sancho, F.; Lucas, F.; Guallar, V.; Kalum, L.; Lund, H.; Gröbe, G.; Scheibner, K.; Ullrich, R.; Hofrichter, M.; Martínez, A. T.; Gutiérrez, A. Steroid hydroxylation by basidiomycete peroxygenases: a combined experimental and computational study. Appl. Environ. Microbiol. 2015, 81, $4130-4142$

(18) Lucas, F.; Babot, E. D.; Cañellas, M.; del Río, J. C.; Kalum, L.; Ullrich, R.; Hofrichter, M.; Guallar, V.; Martínez, A. T.; Gutiérrez, A. Molecular determinants for selective C25-hydroxylation of vitamins D2 and D3 by fungal peroxygenases. Catal. Sci. Technol. 2016, 6, 288-295.

(19) Churakova, E.; Kluge, M.; Ullrich, R.; Arends, I.; Hofrichter, M.; Hollmann, F. Specific Photobiocatalytic Oxyfunctionalization Reactions. Angew. Chem., Int. Ed. 2011, 50, 10716-10719.

(20) Peter, S.; Kinne, M.; Ullrich, R.; Kayser, G.; Hofrichter, M. Epoxidation of linear, branched and cyclic alkenes catalyzed by unspecific peroxygenase. Enzyme Microb. Technol. 2013, 52, 370-376.

(21) Acevedo-Rocha, C. G.; Gamble, C. G.; Lonsdale, R.; Li, A.; Nett, N.; Hoebenreich, S.; Lingnau, J. B.; Wirtz, C.; Fares, C.; Hinrichs, H.; Deege, A.; Mulholland, A. J.; Nov, Y.; Leys, D.; McLean, K. J.; Munro, A. W.; Reetz, M. T. P450-Catalyzed Regio- and Diastereoselective Steroid Hydroxylation: Efficient Directed Evolu- 
tion Enabled by Mutability Landscaping. ACS Catal. 2018, 8, 33953410.

(22) Kille, S.; Zilly, F. E.; Acevedo, J. P.; Reetz, M. T. Regio- and stereoselectivity of P450-catalysed hydroxylation of steroids controlled by laboratory evolution. Nat. Chem. 2011, 3, 738-743.

(23) Kluge, M.; Ullrich, R.; Scheibner, K.; Hofrichter, M. Stereoselective benzylic hydroxylation of alkylbenzenes and epoxidation of styrene derivatives catalyzed by the peroxygenase of Agrocybe aegerita. Green Chem. 2012, 14, 440-446.

(24) Arnold, F. H. When blind is better: protein design by evolution. Nat. Biotechnol. 1998, 16, 617-618.

(25) Reetz, M. T.; Prasad, S.; Carballeira, J. D.; Gumulya, Y.; Bocola, $\mathrm{M}$. Iterative saturation mutagenesis accelerates laboratory evolution of enzyme stereoselectivity: rigorous comparison with traditional methods. J. Am. Chem. Soc. 2010, 132, 9144-9152.

(26) Molina-Espeja, P.; Ma, S.; Mate, D. M.; Ludwig, R.; Alcalde, M. Tandem-yeast expression system for engineering and producing unspecific peroxygenase. Enzyme Microb. Technol. 2015, 73-74, 2933.

(27) Molina-Espeja, P.; Garcia-Ruiz, E.; Gonzalez-Perez, D.; Ullrich, R.; Hofrichter, M.; Alcalde, M. Directed evolution of unspecific peroxygenase from Agrocybe aegerita. Appl. Environ. Microbiol. 2014, 80, 3496-3507.

(28) Martin-Diaz, J.; Paret, C.; García-Ruiz, E.; Molina-Espeja, P.; Alcalde, M. Shuffling the Neutral Drift of Unspecific Peroxygenase in Saccharomyces cerevisiae. Appl. Environ. Microbiol. 2018, 84, No. e00808-18.

(29) Gomez De Santos, P.; Cañellas, M.; Tieves, F.; Younes, S. H. H.; Molina-Espeja, P.; Hofrichter, M.; Hollmann, F.; Guallar, V.; Alcalde, M. Selective Synthesis of the Human Drug Metabolite 5'Hydroxypropranolol by an Evolved Self-Sufficient Peroxygenase. ACS Catal. 2018, 8, 4789-4799.

(30) Mate, D. M.; Palomino, M. A.; Molina-Espeja, P.; Martin-Diaz, J.; Alcalde, M. Modification of the peroxygenative:peroxidative activity ratio in the unspecific peroxygenase from Agrocybe aegerita by structure-guided evolution. Protein Eng., Des. Sel. 2017, 30, 189196.

(31) Carro, J.; González-Benjumea, A.; Fernández-Fueyo, E.; Aranda, C.; Guallar, V.; Gutiérrez, A.; Martínez, A. T. Modulating Fatty Acid Epoxidation vs Hydroxylation in a Fungal Peroxygenase. ACS Catal. 2019, 9, 6234-6242.

(32) Püllmann, P.; Knorrscheidt, A.; Münch, J.; Palme, P. R.; Hoehenwarter, W.; Marillonnet, S.; Alcalde, M.; Westermann, B.; Weissenborn, M. J. A modular two yeast species secretion systemfor the production and preparative applicationof unspecific peroxygenases. Commun. Biol. 2021, 4, 562.

(33) Kluge, M.; Ullrich, R.; Dolge, C.; Scheibner, K.; Hofrichter, M. Hydroxylation of naphthalene by aromatic peroxygenase from Agrocybe aegerita proceeds via oxygen transfer from $\mathrm{H} 2 \mathrm{O} 2$ and intermediary epoxidation. Appl. Microbiol. Biotechnol. 2009, 81, 10711076.

(34) Shukla, S.; Wu, C.-P.; Nandigama, K.; Ambudkar, S. V. The naphthoquinones, vitamin $\mathrm{K} 3$ and its structural analogue plumbagin, are substrates of the multidrug resistance-linked ATP binding cassette drug transporter ABCG2. Mol. Cancer Ther. 2007, 6, 3279.

(35) Poraj-Kobielska, M.; Kinne, M.; Ullrich, R.; Scheibner, K.; Hofrichter, M. A spectrophotometric assay for the detection of fungal peroxygenases. Anal. Biochem. 2012, 421, 327-329.

(36) Püllmann, P.; Ulpinnis, C.; Marillonnet, S.; Gruetzner, R.; Neumann, S.; Weissenborn, M. J. Golden Mutagenesis: An efficient multi-site-saturation mutagenesis approach by Golden Gate cloning with automated primer design. Sci. Rep. 2019, 9, 10932.

(37) Knorrscheidt, A.; Püllmann, P.; Schell, E.; Homann, D.; Freier, E.; Weissenborn, M. J. Identification of novel unspecific peroxygenase chimeras and unusual YfeX axial heme ligand by a versatile highthroughput GC-MS approach. ChemCatChem 2020, 12, 4788-4795.

(38) Cabantous, S.; Waldo, G. S. In vivo and in vitro protein solubility assays using split GFP. Nat. Methods 2006, 3, 845-854.
(39) Sun, Z.; Lonsdale, R.; Li, G.; Reetz, M. T. Comparing Different Strategies in Directed Evolution of Enzyme Stereoselectivity: Singleversus Double-Code Saturation Mutagenesis. ChemBioChem 2016, 17, $1865-1872$.

(40) Sun, Z.; Salas, P. T.; Siirola, E.; Lonsdale, R.; Reetz, M. T. Exploring productive sequence space in directed evolution using binary patterning versus conventional mutagenesis strategies. Bioresour. Bioprocess. 2016, 3, 44.

(41) Widhalm, J. R.; Rhodes, D. Biosynthesis and molecular actions of specialized 1,4-naphthoquinone natural products produced by horticultural plants. Hortic. Res. 2016, 3, 16046.

(42) Mifsud, M.; Gargiulo, S.; Iborra, S.; Arends, I. W. C. E.; Hollmann, F.; Corma, A. Photobiocatalytic chemistry of oxidoreductases using water as the electron donor. Nat. Commun. 2014, 5, 3145.

(43) Rommel, E.; Wirz, J. The photoenol tautomer of 5-methyl-1, 4naphthoquinone. Helv. Chim. Acta 1977, 60, 38-42.

(44) Bakola-Christianopoulou, M. N.; Papageorgiou, V. P.; Apazidou, K. K. Synthesis and gas chromatographic/mass spectrometric study of silylated hydroxyquinones on all hydroxyl groups. Phosphorus, Sulfur Silicon Relat. Elem. 1994, 88, 53-65.

(45) Kille, S.; Acevedo-Rocha, C. G.; Parra, L. P.; Zhang, Z.-G.; Opperman, D. J.; Reetz, M. T.; Acevedo, J. P. Reducing codon redundancy and screening effort of combinatorial protein libraries created by saturation mutagenesis. ACS Synth. Biol. 2013, 2, 83-92.

(46) Acevedo-Rocha, C. G.; Reetz, M. T.; Nov, Y. Economical analysis of saturation mutagenesis experiments. Sci. Rep. 2015, 5, 10654.

(47) Santos-Aberturas, J.; Dörr, M.; Waldo, G. S.; Bornscheuer, U. T. In-Depth High-Throughput Screening of Protein Engineering Libraries by Split-GFP Direct Crude Cell Extract Data Normalization. Chem. Biol. 2015, 22, 1406-1414.

(48) Waterhouse, A.; Bertoni, M.; Bienert, S.; Studer, G.; Tauriello, G.; Gumienny, R.; Heer, F. T.; de Beer, T. A. P.; Rempfer, C.; Bordoli, L.; Lepore, R.; Schwede, T. SWISS-MODEL: homology modelling of protein structures and complexes. Nucleic Acids Res. 2018, 46, W296-W303.

(49) Case, D. A.; Ben-Shalom, I. Y.; Brozell, S. R.; Cerutti, D. S.; Cheatham, T. E., III; Cruzeiro, V. W. D.; Darden, T. A.; Duke, R. E.; Ghoreishi, D.; Gilson, M. K.; Gohlke, H.; Goetz, A. W.; Greene, D.; Harris, R.; Homeyer, N.; Huang, Y.; Izadi, S.; Kovalenko, A.; Kurtzman, T.; Lee, T. S.; LeGrand, S.; Li, P.; Lin, C.; Liu, J.; Luchko, T.; Memelstein, D. J.; Merz, K. M.; Miao, Y.; Monard, G.; Nguyen, C.; Nguyen, H.; Omelyan, I.; Onufriev, A.; Pan, F.; Qi, R.; Roe, D. R.; Roitberg, A.; Sagui, C.; Schott-Verdugo, S.; Shen, J.; Simmerling, C. L.; Smith, J.; Salomon-Ferrer, R.; Swails, J.; Walker, R. C.; Wang, J.; Wei, H.; Wolf, R. M.; Wu, X.; Xiao, L.; York, D. M.; Kollman, P. A. Amber 2018; University of California: San Francisco, 2018.

(50) Li, P.; Merz, K. M. MCPB.py: A Python Based Metal Center Parameter Builder. J. Chem. Inf. Model. 2016, 56, 599-604.

(51) Wang, J.; Wolf, R. M.; Caldwell, J. W.; Kollman, P. A.; Case, D. A. Development and testing of a general amber force field. J. Comput. Chem. 2004, 25, 1157-1174.

(52) Bayly, C. I.; Cieplak, P.; Cornell, W.; Kollman, P. A. A wellbehaved electrostatic potential based method using charge restraints for deriving atomic charges: the RESP model. J. Phys. Chem. A 1993, 97, 10269-10280.

(53) Besler, B. H.; Merz, K. M., Jr.; Kollman, P. A. Atomic charges derived from semiempirical methods. J. Comput. Chem. 1990, 11, 431-439.

(54) Singh, U. C.; Kollman, P. A. An approach to computing electrostatic charges for molecules. J. Comput. Chem. 1984, 5, 129145

(55) Shahrokh, K.; Orendt, A.; Yost, G. S.; Cheatham, T. E., III Quantum mechanically derived AMBER-compatible heme parameters for various states of the cytochrome P450 catalytic cycle. J. Chem. Theory Comput. 2012, 33, 119-133. 
(56) Jorgensen, W. L.; Chandrasekhar, J.; Madura, J. D.; Impey, R. W.; Klein, M. L. Comparison of simple potential functions for simulating liquid water. J. Chem. Phys. 1983, 79, 926-935.

(57) Maier, J. A.; Martinez, C.; Kasavajhala, K.; Wickstrom, L.; Hauser, K. E.; Simmerling, C. ff14SB: Improving the Accuracy of Protein Side Chain and Backbone Parameters from ff99SB. J. Chem. Theory Comput. 2015, 11, 3696-3713.

(58) Darden, T.; York, D.; Pedersen, L. Particle mesh Ewald: AnN. $\log (\mathrm{N})$ method for Ewald sums in large systems. J. Chem. Phys. 1993, 98, 10089-10092.

(59) Roe, D. R.; Cheatham, T. E. PTRAJ and CPPTRAJ: Software for Processing and Analysis of Molecular Dynamics Trajectory Data. J. Chem. Theory Comput. 2013, 9, 3084-3095.

(60) Trott, O.; Olson, A. J. AutoDock Vina: improving the speed and accuracy of docking with a new scoring function, efficient optimization, and multithreading. J. Comput. Chem. 2010, 31, 455461.

(61) Frisch, M. J.; Trucks, G. W.; Schlegel, H. B.; Scuseria, G. E.; Robb, M. A.; Cheeseman, J. R.; Scalmani, G.; Barone, V.; Petersson, G. A.; Nakatsuji, H.; Li, X.; Caricato, M.; Marenich, A. V.; Bloino, J.; Janesko, B. G.; Gomperts, R.; Mennucci, B.; Hratchian, H. P.; Ortiz, J. V.; Izmaylov, A. F.; Sonnenberg, J. L.; Williams-Young, D.; Ding, F.; Lipparini, F.; Egidi, F.; Goings, J.; Peng, B.; Petrone, A.; Henderson, T.; Ranasinghe, D.; Zakrzewski, V. G.; Gao, J.; Rega, N.; Zheng, G.; Liang, W.; Hada, M.; Ehara, M.; Toyota, K.; Fukuda, R.; Hasegawa, J.; Ishida, M.; Nakajima, T.; Honda, Y.; Kitao, O.; Nakai, H.; Vreven, T.; Throssell, K.; Montgomery, J. A., Jr.; Peralta, J. E.; Ogliaro, F.; Bearpark, M. J.; Heyd, J. J.; Brothers, E. N.; Kudin, K. N.; Staroverov, V. N.; Keith, T. A.; Kobayashi, R.; Normand, J.; Raghavachari, K.; Rendell, A. P.; Burant, J. C.; Iyengar, S. S.; Tomasi, J.; Cossi, M.; Millam, J. M.; Klene, M.; Adamo, C.; Cammi, R.; Ochterski, J. W.; Martin, R. L.; Morokuma, K.; Farkas, O.; Foresman, J. B.; Fox, D. J. Gaussian 16, Revision C.01; Gaussian Inc.: Wallingford, CT, 2016.

(62) Becke, A. D. Density-functional exchange-energy approximation with correct asymptotic behavior. Phys. Rev. A: At., Mol., Opt. Phys. 1988, 38, 3098-3100.

(63) Becke, A. D. Density-functional thermochemistry. III. The role of exact exchange. J. Chem. Phys. 1993, 98, 5648-5652.

(64) Lee, C.; Yang, W.; Parr, R. G. Development of the ColleSalvetti correlation-energy formula into a functional of the electron density. Phys. Rev. B: Condens. Matter Mater. Phys. 1988, 37, 785-789.

(65) Barone, V.; Cossi, M. Quantum Calculation of Molecular Energies and Energy Gradients in Solution by a Conductor Solvent Model. J. Phys. Chem. A 1998, 102, 1995-2001.

(66) Cossi, M.; Rega, N.; Scalmani, G.; Barone, V. Energies, structures, and electronic properties of molecules in solution with the C-PCM solvation model. J. Comput. Chem. 2003, 24, 669-681.

(67) Schutz, C. N.; Warshel, A. What are the dielectric "constants" of proteins and how to validate electrostatic models? Proteins 2001, 44, 400-417. 